\title{
A Study on the Effect of Glucagon Like Peptide 1 Agonist on Glycemic State, Renal Functions and Some Hemodynamic Parameters in Diabetic Male Albino Rats
}

\author{
SOHEIR A. SALEH, M.D.*; SHAIMAA M. MOTAWEA, M.D.*; AHMAD M. GAFFER, M.D.*; \\ ALSHAIMAA E. MOHAMED, M.Sc.** and SUZY F. EWIDA, M.D.*
}

The Department of Physiology, Faculty of Medicine, Menoufia* and Kafr Elshiekh** Universities

\begin{abstract}
Background: Vascular and renal complications are common associations to diabetes mellites despite current therapies. Glucagon like peptide 1 may present a recent solution to these complications and provide a better control.

Aim of Study: This investigation aimed to study the effects of glucagon like peptide 1 receptor agonist on induced type 2 diabetes mellitus and the possible underlying mechanisms.

Methods: Fifty male albino rats classified into five groups, 10 rats each: Non diabetic, diabetic non treated, diabetic metformin-treated, exendin-4 treated diabetic and combined metformin \& exendine-4 treated diabetic groups. After 7 weeks, systolic blood pressure, renal blood flow and renal resistance were measured. Urine volume per minute, urine creatinine, creatinine clearance, fasting blood glucose, glycosylated hemoglobin (HbA1c \%), serum insulin, serum glucagon, blood urea nitrogen, total anti-oxidant capacity, serum malondialdehyde (MDA) and serum tumor necrosis factor alpha (TNFa) were assessed.

Results: The diabetic metformin, exendine-4-and combined metformin \& exendine-4-treated groups revealed significant improvement in glycemic state, oxidative stress, inflammatory state, hemodynamic parameters and renal functions compared to the corresponding values of diabetic non-treated group. Exendin-treated group significantly decreased the previously mentioned parameters plus glucagon level compared to diabetic non-treated and diabetic metformin-treated groups. Combined metformin \& exendine-4-treated group showed improvement of all previously mentioned parameters more than each treatment alone.

Conclusion: Exendine-4 treatment improved diabetic parameters and associated hemodynamic and renal complications more effective than that of the specific agents as metformin. Combined metformin treatment with exendine-4 showed significant improvement than that of using each of them alone.
\end{abstract}

Correspondence to: Dr. Al-Shaimaa E. Mohammed, E-Mail: shaimaaibrahim2014@yahoo.com
Key Words: Exendin-4 - Diabetes - Glucagon-GlucoseMetformin-Renal function.

\section{Introduction}

DIABETES mellitus is one of the common metabolic disorders which presented by chronic elevation of glucose in the blood [1]. Diabetic patients fall in two etiopathogenic categories; type 1 diabetes mellitus (slightly rare type) resulted from absolute deficiency of insulin secretion, type 2 diabetes mellitus (most common type) resulted from insulin resistance with inadequate secretion of insulin as a compensatory response [2] .

Hyperglycemia has a central role in the pathogenesis of macro-and micro-vascular complication as it induces endoplasmic reticulum stress with mitochondrial dysfunction. Consequently this activates the production and accumulation of Reactive Oxygen Species (ROS) which promotes cellular dysfunction and injury. Permanent oxidative modifications occurs as ROS can directly destroy the lipids, proteins or DNA component and interfering with intracellular signaling pathways [3].

Kidney disease attributed to diabetes is a major but under-recognized contributor to the global burden of disease. Chronic Kidney Disease (CKD) develops in approximately $40 \%$ of diabetic patients and attributed to $94 \%$ number of deaths. CKD caused by associated metabolic changes that lead to glomerular hypertrophy, glomerulo sclerosis, and tubulointerstitial inflammation and fibrosis despite current therapies [4].

Metformin is one of the most commonly prescribed drug for the treatment of type 2 diabetes mellitus due to its efficacy and safety [5]. It is an 
insulin-sensitizing biguanide, as its inhibition on hepatic gluconeogenesis and insulin sensitizing action help in diabetes mellitus management [6] .

Glucagon Like Peptide 1 (GLP-1) receptor agonist, as exenatide, stimulates insulin secretion and inhibits glucagon secretion and hepatic glucose production in a glucose-dependent manner. In addition, it also delays gastric emptying and suppresses appetite through the central pathways. Although it may provide the benefit of reducing Body Weight (BW) and it also offers better sugar control in diabetic cases [7].

The aim of this work was to study the effects of glucagon like peptide 1 receptor agonist (exenatide) on glycemic state, renal functions and some hemodynamic parameters in diabetic male albino rats and the possible mechanisms underlying this effect.

\section{Material and Methods}

\section{Animals:}

This study was conducted during the period from 23/7/2018 to 23/9/2018 in the laboratories of the Faculty of Medicine at Kafr Al-Sheikh University on 50 male albino rats of local strain weighting 200-250g. Rats were housed (5 rats per cage) at room temperature, with a 12-hr light-dark cycle (light on at 8:00a.m. and off at 8:00p.m.). They were allowed free access to food and water all over the period of the work. This experiment was approved by the Research Ethics Committee at Faculty of Medicine Menoufia University.

Animals were classified into five groups each contains 10 rats:

I- Non-Diabetic (ND); rats with fasting blood glucose level less than $110 \mathrm{mg} / \mathrm{dl}$ and using a single intraperitoneal injection of $0.2 \mathrm{ml}$ of $10 \mathrm{mmol} / 1$ citrate buffer (STZ vehicle).

II- Type II diabetic non-treated (DN); diabetes type 2 was induced by single intraperitoneal injection of $45 \mathrm{mg} / \mathrm{kg}(1.0 \mathrm{ml} / \mathrm{kg}$ ) of streptozotocin (Sigma chemical company, Saint Louis, USA) [8]. Three days after rats with fasting blood glucose > 160 $\mathrm{mg} / \mathrm{dl}$ were considered diabetic and included in the study.

III- Type II diabetic metformin-treated (D-met); diabetic animals, as previously described, were given metformin (CID-company, Egypt) in a dose of $150 \mathrm{mg} / \mathrm{kg}$ body weight orally (6 days/week) by oral gavage [9]

IV- Type II diabetic exendin-4 treated (D-exe); diabetic animals, as previously described, were injected by exendin-4 (Bachem, Bubendorf, Switzerland) intraperitonealy at $10 \mathrm{~g} / \mathrm{kg}$ body weight daily [10].

V- Combined Type II diabetic metformin \& exendine-4 treated (D-met + exe); diabetic animals, as previously described, received both metformin orally and intraperitoneal injection of exendin- 4 .

At the end of experimental period (7 weeks), systolic blood pressure was measured, urine samples were collected using metabolic cages for measuring urine volume per minute $(\mathrm{ml} / \mathrm{min})$, urine creatinine concentration $(\mathrm{mg} / \mathrm{ml})$. The next day after one night fasting rats were then anaesthetized and abdominal wall was opened for exposure of renal artery and renal blood flow \& renal resistance were measured. Fasting blood samples were taken from abdominal aorta for measuring fasting blood glucose ( $\mathrm{mg} / \mathrm{dl})$, glycosylated hemoglobin (HbA1c $\%)$, serum insulin $(\mu \mathrm{u} / \mathrm{ml})$, serum glucagon, serum creatinine $(\mathrm{mg} / \mathrm{dl})$, blood urea nitrogen $(\mathrm{mg} / \mathrm{dl})$, total anti-oxidant capacity ( $\mathrm{mmol} / \mathrm{L})$, serum malondialdehyde (MDA $(\mu \mathrm{mol} / \mathrm{L})$ and serum tumor necrosis factor alpha (TNF $(\mathrm{x})(\mathrm{pg} / \mathrm{ml})$. Then creatinine clearance $(\mathrm{ml} / \mathrm{min})$ and HOMA-IR index were calculated.

Measurement of arterial blood pressure: Systolic blood pressure $(\mathrm{mmHg})$ was monitored by a rat-tail sphygmomanometer and a pneumatic pulse transducer. The pneumatic cuff over the rat's tail inflated over $200 \mathrm{mmHg}$ to occlude the pulse and allowed to deflate slowly until the pulse pressures were observed on the pulse channel of the recorder. A two channel recorder was used to obtain a written record of both blood flow and cuff pressure [8]

Measurement of Renal Blood Flow (RBF) and Renal vascular Resistance (RVR):

All rats were anesthetized using thiopental sodium $(50 \mathrm{mg} / \mathrm{kg}$ ) (I.P.) [9]. All rats had surgical exposure of the left and right renal pedicles through midline incision [10]. After setting the mode of pulsed blood flow meter (Doppler), we used ultrasonic gel on the probe top and turned the volume control to the maximum. The probe pressed softly to the measured area at an angle of $45-50^{\circ}$. After hearing the optimal sounds, we wait for 5 second without moving the probe then press the freeze key to freeze the waveform [11].

Biochemical assay of different blood parameters:

Blood Glucose: Estimation of Fasting Blood Glucose (FBG) using fasting blood glucose kits (Sigma-Aldrish, USA) [12] 
Glycated Hemoglobin (HbAl c\%): Estimation of glycated hemoglobin as percentage of total hemoglobin (HbA1c) using HbA1c kits [13].

Serum insulin: Estimation of serum insulin using serum insulin kits [14]

Homeostasis Model Assessment Index (HOMA$I R$ ): Insulin resistance was detected by using fasting blood glucose and serum insulin calculating HOMA -IR index as follow [15]:

Fasting serum insulin $(\mu \mathrm{u} / \mathrm{ml}) \mathrm{X}$ fasting blood glucose $\mathrm{mg} / \mathrm{dl}$

405

Serum glucagon: Determination of Serum glucagon using Quantikine ${ }^{\circledR}$ ELISA kits China [16].

Blood urea nitrogen (BUN): Determination of BUN using kits for estimation of BUN [17]

Serum creatinine: Determination of serum creatinine using Kits for estimation of fasting serum creatinine [18].

Total anti-oxidant capacity (TAC): Estimation of total antioxidant capacity using serum TAC ELISA kits [19].

Serum malondialdehyde (MDA): Assay of malondialdehyde (MDA) using serum MDA ELISA kits [20].

Serum tumor necrosis factor alpha (TNF $\alpha)$ : Estimation of serum tumor necrosis factor alpha (TNF $\alpha$ ) using serum TNF $\alpha$ ELISA kits [21].

\section{Statistical analysis:}

The data were shown as the mean \pm standard deviation. Data from the study were analyzed using by one-way Analysis of Variance (ANOVA) followed by Tukey's test to assess the significance. The $p<0.05$ were considered as statistically significant. Using SPSS for windows (Version 23.0).

\section{Results}

Glycemic state parameters (fasting serum glucose, glycated hemoglobin levels and HOMA-IR), renal functions tests (serum creatinine and BUN) oxidative stress and inflammatory marker parameters (MDA and TNF $\alpha$ ) in DN, D-met., D-exe. \& D-met. + exe. groups showed significant elevation compared to corresponding values of ND group. D-met., D-exe. \& D-met. + exe. groups showed significant reduction compared to corresponding value of DN group. D-exe. \& D-met. + exe. groups showed significant reduction compared to corresponding values of D-met group. D-met. + exe. group showed significant reduction compared to corresponding values of D-exe. group (Table 1).

Fasting serum insulin level in DN, D-met., Dexe. \& D-met. + exe. groups showed significant reduction compared to corresponding value of $\mathrm{ND}$ group. D-exe. \& D-met. + exe. groups showed significant elevation compared to corresponding value of DN and D-met groups. D-met. + exe. showed significant elevation compared to corresponding value of D-exe. group (Table 1).

Serum glucagon level in DN, D-met., D-exe. \& D-met. + exe groups showed significant elevation when compared to corresponding value of $\mathrm{ND}$ group. D-exe. \& D-met. + exe. groups showed significant reduction compared to corresponding value of DN and D-met groups. D-met. + exe. group showed insignificant reduction compared to corresponding value of D-exe group (Table 1).

Creatinine clearance and TAC in DN, D-met, D-exe. \& D-met. + exe. groups showed significant reduction compared to corresponding values of ND group. D-met., D-exe. \& D-met. + exe. groups showed significant elevation compared to corresponding values of DN group. D-exe. \& D-met. + exe. groups showed significant elevation compared to corresponding values of D-met group. D-met. + exe. group showed significant elevation compared to corresponding values of D-exe group (Table 1).

\section{Hemodynamic parameters:}

Systolic blood pressure and renal resistance in DN, D-met., D-exe. \& D-met. + exe. groups showed significant elevation when compared to corresponding values of ND group. D-met., D-exe. \& D-met. + exe. groups showed significant reduction compared to corresponding values of DN group. Dexe. \& D-met. + exe. groups showed significant reduction compared to corresponding values of $\mathrm{D}$ met group. D-met. + exe. group showed significant reduction compared to corresponding values of Dexe. group (Table 2) and Figs. $(1,2)$.

Renal blood flow in DN, D-met., D-exe. \& Dmet. + exe. groups showed significant reduction when compared to corresponding value of ND group. D-met., D-exe. \& D-met. + exe. groups showed significant elevation compared to corresponding value of DN group. D-exe. \& D-met. + exe. groups showed significant elevation compared to corresponding value of D-met group. D-met. + exe. group showed significant elevation compared to corresponding value of D-exe. group (Table 2) and Fig. (2). 


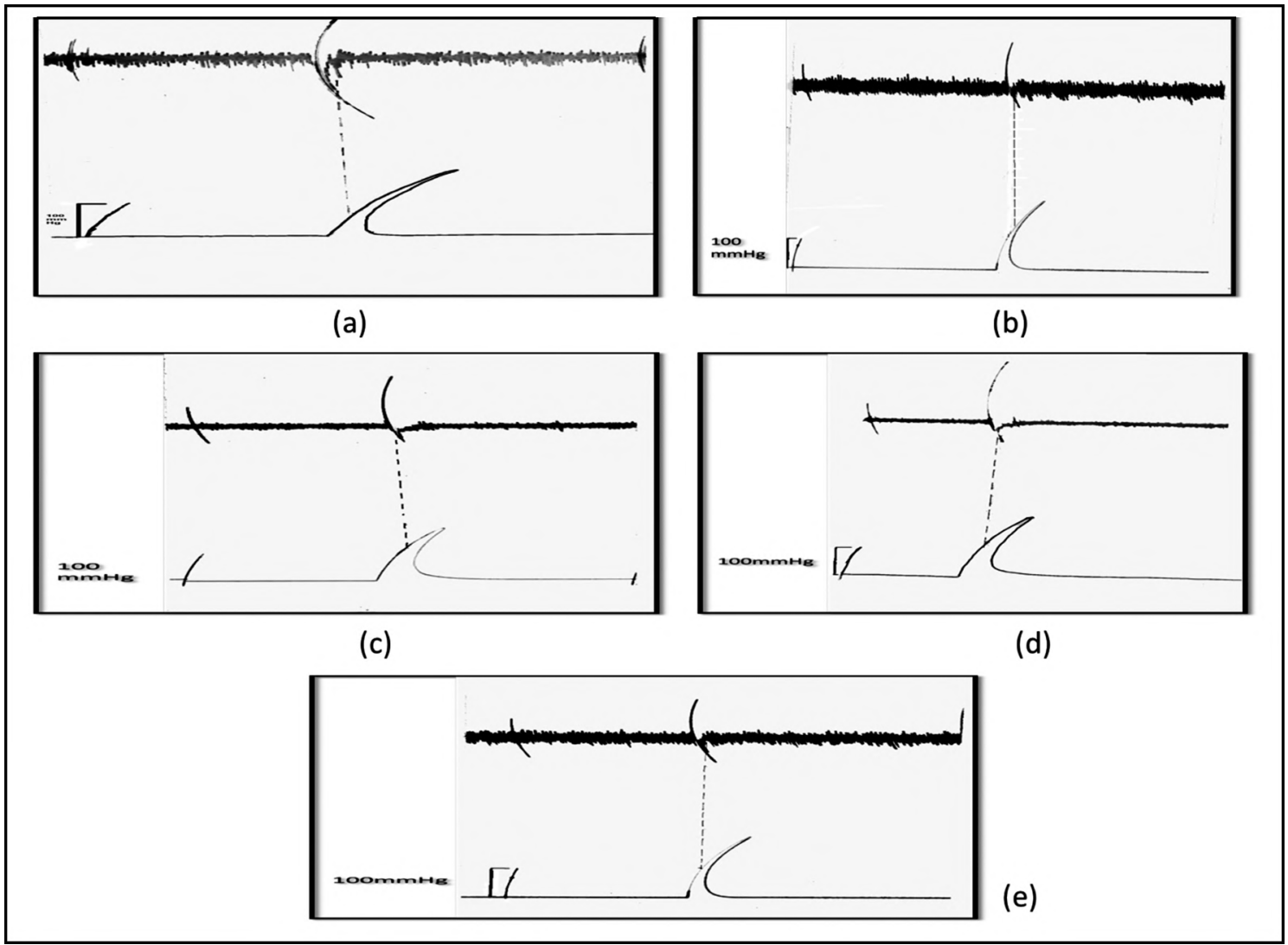

Fig. (1): A sample record of systolic blood pressure in (A) Non-diabetic group, (B) Diabetic non treated group, (C) Diabetic metformin treated group, (D) Diabetic exendine-4 treated group and (E) Diabetic mrtformin + exendine-4 treated group.

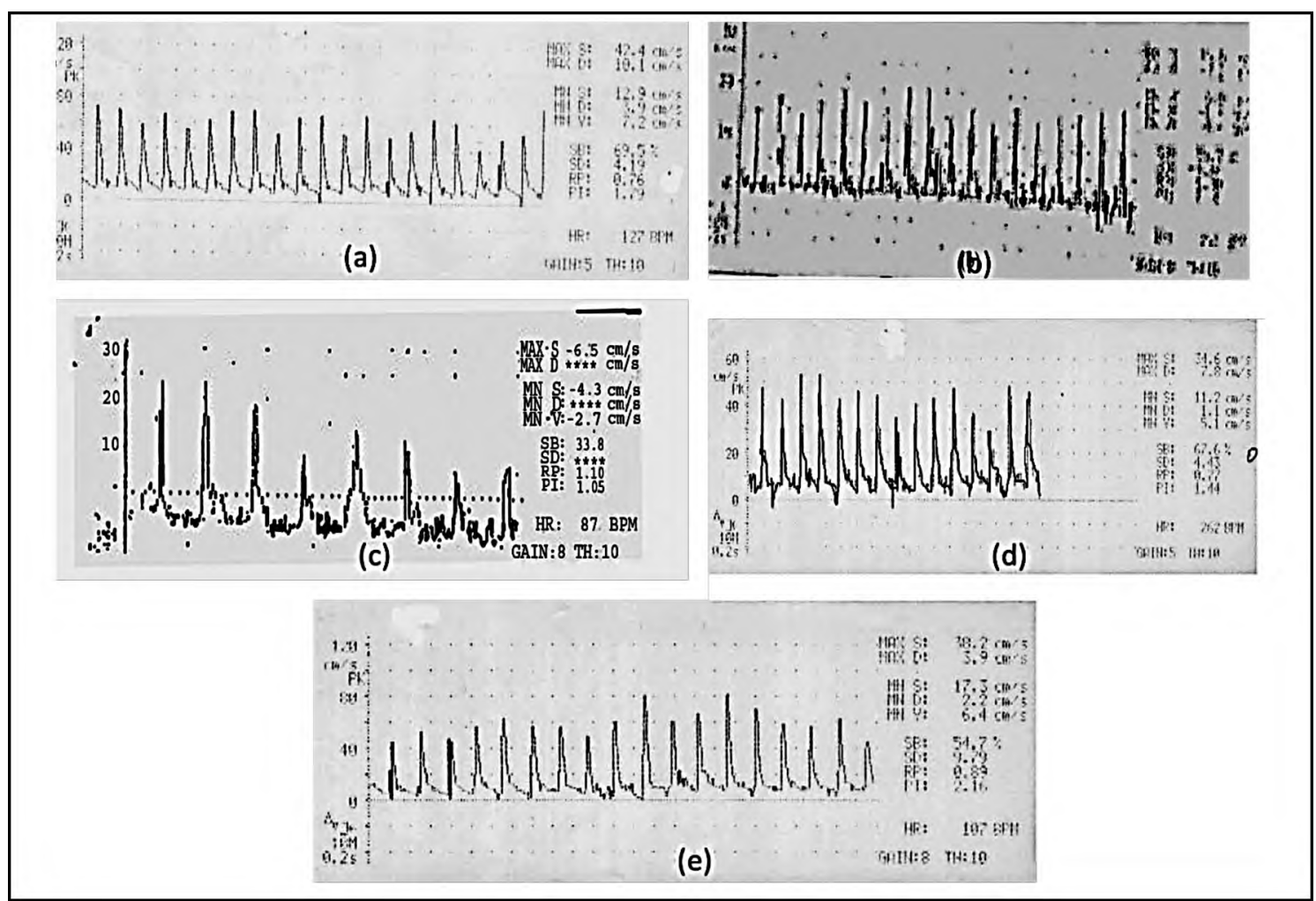

Fig. (2): A sample record of renal blood flow velocity and renal resistance in (A) Non-diabetic group, (B) Diabetic non treated group, (C) Diabetic metformin treated group, (D) Diabetic exendine-4 treated group and (E) Diabetic mrtformin + exendine-4 treated group. 
Table (1): Glycemic state parameters (fasting blood glucose, glycated hemoglobin, fasting serum insulin, HOMA-IR), fasting serum glucagon, renal functions parameters (blood urea nitrogen, serum creatinine, creatinine clearance), oxidative stress parameters (total anti-oxidant capacity, serum malonaldehyde) and inflammatory marker (tumour necrosis factor $\alpha$ ) in non-diabetic (ND), diabetic non treated (DN), diabetic metformin treated (D-met.), diabetic exendine-4 treated (D-exe.) and diabetic metformin + exendine-4 treated (D-met. + exe.) groups.

\begin{tabular}{|c|c|c|c|c|c|}
\hline & ND & DN & D-met. & D-exe. & D-met. + exe. \\
\hline Fasting blood glucose (mg/dl) & $80.49 \pm 0.08$ & $229.2 \pm 0.25 *$ & $122.2 \pm 0.25 * \#$ & 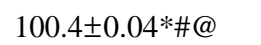 & 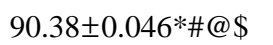 \\
\hline HBA1C $\%$ & $.24 \pm 0.014$ & $8.39 \pm 0.019 *$ & $4.23 \pm 0.01 * \#$ & 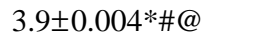 & $3.2 \pm 0.005 * \# @ \$$ \\
\hline Fasting serum insulin ( $\mathbf{p} / \mathbf{l})$ & $14.42 \pm 0.03$ & $7.69 \pm 0.04 *$ & $7.88 \pm 0.03 *$ & $11.28 \pm 0.032 * \# @$ & $12.31 \pm 0.034 * \# @ \$$ \\
\hline HOMA-IR & $2.86 \pm 0.004$ & $4.35 \pm 0.02 *$ & $3.12 \pm 0.013 * \#$ & $3.03 \pm 0.008 * \# @$ & $2.96 \pm 0.009 * \# @ \$$ \\
\hline Fasting serum glucagon $(\mathrm{ng} / \mathrm{ml})$ & $241.62 \pm 0.03$ & $780.46 \pm 0.04 *$ & $778.23 \pm 0.03 *$ & $257.93 \pm 0.032 * \# @$ & 255.47士0.034*\#@\$ \\
\hline BUN (mg/dl) & $25.09 \pm 0.19$ & $70.6 \pm 0.37 *$ & $42.59 \pm 0.38 * \#$ & 38.5×0.004*\#@ & 35.49土0.005*\#@\$ \\
\hline Serum creatinine $(\mathrm{mg} / \mathrm{dl})$ & $0.65 \pm 0.005$ & $2.165 \pm 0.015^{*}$ & $1.23 \pm 0.012 * \#$ & $1.01 \pm 0.004 * \# @$ & $0.84 \pm 0.005 * \# @ \$$ \\
\hline Creatinine clearance ( $\mathrm{ml} / \mathrm{min})$ & $1.2 \pm 0.005$ & $0.58 \pm 0.005 *$ & $1.02 \pm 0.006 * \#$ & 1.1土0.04*\#@ & $1.15 \pm 0.05$ *\#@\$ \\
\hline TAC (mmol/L) & $2.64 \pm 0.003$ & $0.84 \pm 0.005 *$ & $2.03 \pm 0.004 * \#$ & $2.23 \pm 0.005 * \# @$ & $2.37 \pm 0.007 * \# @ \$$ \\
\hline MDA ( $\mathrm{mal} / \mathrm{L})$ & $2.84 \pm 0.006$ & $9.28 \pm 0.009 *$ & $6.43 \pm 0.008 * \#$ & 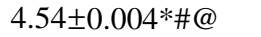 & $3.04 \pm 0.007 * \# @ \$$ \\
\hline TNF- $\alpha(\mathrm{Pg} / \mathrm{ml})$ & $20.76 \pm 0.003$ & $57.8 \pm 0.03 *$ & $39.36 \pm 0.005 * \#$ & 30.25士0.004*\#@ & $21.83 \pm 0.005 * \# @ \$$ \\
\hline
\end{tabular}

Number of rats in each group was 10 .

$p$-value $<0.05$ is significant.

*: Significant when compared to non-diabetic.

\# : Significant when compared to diabetic non-treated.

@ : Significant when compared to diabetic-metformin treated.

\$ : Significant when compared to diabetic exendine-4 treated.

Table (2): Systolic blood pressure, renal blood flow velocity and renal resistance in non-diabetic (ND), diabetic non treated (DN), diabetic metformin treated (D-met.), diabetic exendine-4 treated (D-exe.) and diabetic metformin + exendine4 treated (D-met. + exe.) groups.

\begin{tabular}{|c|c|c|c|c|c|}
\hline & ND & DN & D-met. & D-exe. & D-met. + exe. \\
\hline $\mathrm{SBP}(\mathrm{mmHg})$ & $91.7 \pm 0.07$ & $120.5 \pm 0.004 *$ & $100.9 \pm 0.35 * \#$ & 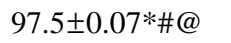 & 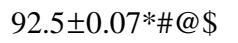 \\
\hline Renal blood flow velocity $(\mathrm{cm} / \mathrm{sec})$ & $5.63 \pm 0.07$ & $4.64 \pm 0.004 *$ & $5.15 \pm 0.006^{* \#}$ & $5.21 \pm 0.007 * \# @$ & $5.47 \pm 0.005^{* \# @ \$ ~}$ \\
\hline Renal resistance (PRU) & $0.76 \pm 0.005$ & $1.68 \pm 0.008 *$ & $1.1 \pm 0.006^{* \#}$ & $1.01 \pm 0.007 * \# @$ & $0.90 \pm 0.0478 \# @ \$$ \\
\hline $\begin{array}{l}\text { Number of rats in each group was } 10 . \\
p \text {-value }<0.05 \text { is significant. } \\
* \text { : Significant when compared to non-dia }\end{array}$ & & $\begin{array}{l}\#: \mathrm{Si} \\
@: \mathrm{S} \\
\$: \mathrm{Si}\end{array}$ & $\begin{array}{l}\text { ificant when com } \\
\text { nificant when con } \\
\text { ificant when com }\end{array}$ & $\begin{array}{l}\text { red to diabetic non-t } \\
\text { ared to diabetic-metf } \\
\text { red to diabetic exen }\end{array}$ & $\begin{array}{l}\text { ated. } \\
\text { min treated. } \\
\text { he-4 treated. }\end{array}$ \\
\hline
\end{tabular}

\section{Discussion}

In the present investigation, diabetic rat model was successfully established by STZ injection as evidenced by the significant elevation of blood glucose and glycated hemoglobin and this was associated with significant decrease in serum insulin level and significant increase in serum glucagon level and insulin resistance. Destruction of pancreatic $\beta$-cells can be caused by the injected STZ, due to its accumulation in pancreatic $\beta$-cells via uptake by Glucose transporter (GLUT2) inducing multiple DNA strand breaks and increased the $\beta$-cells oxidative stress [22]. Increased insulin resistance in the present investigation can be explained by the significant elevation of serum TNF- $\alpha$ of diabetic non-treated group [23].

The inappropriate increased alpha-cell function reflects the loss of tonic inhibition normally exerted by high local concentrations of insulin on alphacells, possibly as a result of beta-cell failure and alpha-cell insulin resistance [24].

Concerning hemodynamic parameters in the present investigation, systolic blood pressure level and renal resistance were significantly higher in diabetic non-treated group, while renal blood flow was significantly lower. The deteriorated hemodynamic parameters can be explained by the associated hyperglycemia, insulin deficiency and oxidative stress detected in the previously mentioned group. Insulin has a role in vasodilatation by enhancing endothelial nitric oxide production through activation of the phosphatidylinositol 3-kinase pathway. While insulin resistance was associated with impairment in this pathway and the mitogenactivated protein kinase leading to enhancement of vasoconstrictions [25]. Renal impairment detected from the elevated BUN and serum creatinine levels in diabetic group was in agreement with several other studies [26-28] which can be explained by increased renal artery resistance, oxidative stress and elevated inflammatory marker presented in this investigation.

Treatment of diabetic rats with metformin revealed significant improvement in glycemic state, oxidative stress, inflammatory state, hemodynamic parameters and renal functions. Metformin suppressed the basal glucose production in liver cells 
by inhibiting gluconeogenesis and by increasing glucose uptake and storage in skeletal muscle [29]

The ability of metformin to ameliorate oxidative stress-induced damage associated with streptozotocin-induced diabetes resulted from its antihyperglycemic effect, insulin action improvement and enhancement of the cellular response to insulin [30].

It modulates the concentration of $\mathrm{C}$-reactive protein in type 2 diabetes, reduces levels of proinflammatory cytokines and reduces activation of the transcription factor nuclear factor kappa B by activated cytokines with improvement in glucose tolerance independently of glycemic control [31].

Metformin can inhibit the fibrosis of tubulointerstitial and epithelial mesenchymal transition in vitro and in vivo models by stimulation of AMPK and inhibition of the collagen deposition and downregulation of transforming growth factor- $\beta 1$ in renal fibroblasts [32].

Metformin has a potent protective action on vascular cells as it modifies the vascular function and reduces the incidence of diabetes-associated vascular complications by the improvement of glycemic control, decreased the insulin resistance, normalized the lipid profile, and inhibition of the oxidative stress [33].

Results of this study revealed that administration of exendine-4 (GLP-1) led to improvement in glycemic state, oxidative stress, inflammatory state, hemodynamic parameters and renal functions and lowered blood glucagon level.

Glp-1 improves the hyperglycemia in type 2 diabetic patients as they increase postprandial insulin secretion, inhibit glucagon secretion, slow gastric emptying and induce satiety. Glp-1 lowers glucagon concentration (fasting and postprandial) [34].

GLP-1 decreases oxidative stress in diabetes mellitus as treatment of GLP-1 or its receptor agonist shows significant reductions in oxidative stress markers (superoxide dismutase, glutathione reductase, catalase, glutathione peroxidase, glutathione levels, lipid peroxidation, and nonenzymatic glycosylated proteins) induced by various stress factors. The mechanism of its antioxidative action was found to be via a receptormediated activation of cAMP, PI3K, and PKC pathways, which consequently increases the antioxidant capacity [35].
GLP-1 receptor is widely expressed in the vasculature; its stimulation causes vasorelaxation in the isolated rat aorta and femoral artery and increases blood flow in the forearm or the brachial artery in humans. The GLP- 1 receptor is also expressed in the renal artery [36]. Which explains the improvement in hemodynamic parameters in the result of this study and in that of Okerson and his colleagues [37]. They correlated the reduction in systolic systolic blood pressure of diabetic hypertensive patients with administration of fixeddose of exenatide.

Renal function improvement in this study was in agreement with El-Gohary and Said [38] reported that pretreatment of rats with GLP-1 produced asignificant reduction in the serum levels of BUN and creatinine in diabetics. The mechanism of this improvement was based onthe amelioration of the oxidative stress and the reduction of the inflammatory markers which are major precipitating factors for renal function impairment. The reno-protective effect of GLP-1 receptor agonist medications against nephropathy has been proven in animal and human studies [39].

In the present study combined treatment of streptozotocin induced diabetic rats by both exendine-4 \& metformin resulted in significant improvement in glycemic state, oxidative stress, inflammatory state, hemodynamic parameters and renal functions when compared to non-treated group or treated group with each single drug. The improvement in all previously investigated parameters can be explained on the basis of combination of hypoglycemic, antioxidant and anti-inflammatory effects of both drugs in addition to the glucagon lowering effect of exendine- 4 .

The results of the present study were in accordance to the result of Reid, [40] who reported that, additional complementary actions between metformin and a DPP-4 inhibitor or a GLP-1RA. Also, these results coincide with [41] who stated that the newer incretin based therapies are appropriate for use in combination with more traditional agents (eg, metformin, TZDs, insulin) to reduce glycosylated hemoglobin without increasing the risk of hypoglycemia. In addition, because these newer agents act on different pathways, the beneficial actions on glycemia and weight are likely additive when used in combination.

\section{Conclusion:}

From the results of the present investigation it can be concluded that: Exendine-4 treatment improves the glycemic state as it decreases fasting 
serum glucose, glycosylated hemoglobin and decreases insulin resistance and improves the renal functions in diabetic rats. Combined metformin treatment with exendine- 4 resulted in significant improvement of the glycemic state, renal functions and some hemodynamic parameters in diabetic rats. This improvement was better than that of using each of them alone and this may indicate that exendine- 4 had a complementary effect to metformin treatment in type II diabetes mellitus. So, exendine- 4 is a promising adjuvant therapy for type II diabetes mellitus and is considered a lamp in the dark tunnel of diabetes mellitus.

\section{References}

1- TRIPATHI P., GUPTA G. and CHAUHAN P.S.: "Role of Phytomedicine in Diabetes and Cardiovascular Diseases". New Look to Phytomedicine: Elsevier, 403-409, 2019.

2- RESMINI E., MINUTO F., COLAO A. and FERONE D.: "Secondary diabetes associated with principal endocrinopathies: The impact of new treatment modalities". Acta diabetologica, 46 (2): 85-95, 2009.

3- FIORENTINO V.T., PRIOLETTA A., ZUO P. and FOLLI F.: "Hyperglycemia-induced oxidative stress and its role in diabetes mellitus related cardiovascular diseases". Current pharmaceutical design, 19 (32): 5695-703, 2013.

4- ALICIC R.Z., ROONEY M.T. and TUTTLE K.R.: "Diabetic kidney disease: Challenges, progress, and possibilities". Clin. J. Am. Soc. Nephrol., 12: 2032-45, 2017.

5- JONES K.L., ARSLANIAN S., PETEROKOVA V.A., PARK J.S. and TOMLINSON M.J.: "Effect of metformin in pediatric patients with type 2 diabetes: A randomized controlled trial". Diabetes care, 25 (1): 89-94, 2002.

6- BOYLE J., MCKEY G. and FISHER M.: "Drugs for diabetes: Part 1 metformin". Braz J. Cardiol., 17: 231-4, 2010.

7- MARÍN-CASINO M. and PASCUAL J.: "Treating posttransplantation diabetes mellitus". AU-Pérez-Sáez, María José. Expert opinion on pharmacotherapy, 16: 1435-48, 2015.

8- LATHA M. and PARI L.: "Antihyperglycaemic effect of Cassia auriculata in experimental diabetes and its effects on key metabolic enzymes involved in carbohydrate metabolism". Clinical and experimental pharmacology and physiology, 30 (1-2): 38-43, 2003.

9- SHIRALI S., BABAALI S. and BABAALI H.: "A Comparative Study on the Effects of Incretin and Metformin on sugar Profile and Insulin Resistance in STZ-induced Diabetic Wistar Rats". RJPBCS, 7 (5): 1921-9, 2016.

10- MONDRAGON A., DAVIDSSON D., KYRIAKOUDI S., BERTLING A., GOMES-FARIA R., COHEN P. and DA SILVA XAVIER G.: "Divergent effects of liraglutide, exendin-4, and sitagliptin on beta-cell mass and indicators of pancreatitis in a mouse model of hyperglycaemia". PloS one, 9 (8): e104873, 2014.

11- ULLIAN M.E., ISLAM M.M., ROBINSON C.J., FITZGIBBON W.R., TOBIN E.T., et al.: "Resistance to mineralocorticoids in Wistar-Furth rats". Am. J. Physiol. Heart Circ. Physiol., 272: H1454- H1461, 1997.
12- KULTHINEE S., WYSS J.M., JIRAKULSOMCHOK D., and ROYSOMMUTI S.: "High sugar intake exacerbates cardiac reperfusion injury in perinatal taurine depleted adult rats". Journal of biomedical science, 17 Suppl 1 (Suppl 1), S22. doi: 10.1186/1423-0127-17-S1-S22, 2010.

13- EL-GOHARY O.A. and SAID M.A.: "Protective effect of exenatide (glucagon-like peptide-1 receptor agonist) on renal ischemia-reperfusion injury in diabetic rats". Benha Medical Journal, 33: 24, 2016.

14- HAYWOOD J.R., SHAFFER R.A., FASTENOW C., FINK G.D. and BRODY M.J.: "Regional blood flow measurement with pulsed Doppler flowmeter in conscious rat". Am. J. Physiol. Heart Circ. Physiol., 241: H273$\mathrm{H} 278,1981$.

15- TRINDER P.: "Enzymatic colorimetric method for determination of glucose, cholesterol and triglycerides" Ann. Clin. Bioche, 6: 24-7, 1969.

16- GONEN B. and RUBENSTEIN A.H.: "Haemoglobin A1 and diabetes mellitus". Diabetologia, 15 (1): 1-8, 1978.

17- JUDZEWITSCH R., PFEIFER M., BEST J., et al.: "Chronic chlorpropamide therapy of non-insulin dependent diabetes augments and stimulated insulin secretion by increasing islet sensitivity to glucose". J. Clin. End. and Metab., 55: 321-8, 1982.

18- MATTHEWS D., HOSKER J., RUDENSKI A., et al.: "Homeostasis model assessment: Insulin resistance and beta cell function from fasting plasma glucose and insulin concentrations in man". Diabetologia, 28: 412-9, 1985.

19- ZHOU D., CHEN Y.W., ZHAO Z.H., YANG R.X., XIN F.Z., LIU X.L. and FAN J.G.: "Sodium butyrate reduces high-fat diet-induced non-alcoholic steatohepatitis through upregulation of hepatic GLP-1R expression". Experimental \& molecular medicine, 50 (12): 157, 2018.

20- SUN T., DONG W., JIANG G., YANG J., LIU J., ZHAO L. and MA P.: "Cordyceps militaris Improves Chronic Kidney Disease by Affecting TLR4/NF- icB Redox Signaling Pathway". Oxidative medicine and cellular longevity, 2019.

21- FOLIN O. and WU H.: "Jaffe method for creatinine estimation". J. Biol. Chem., 38: 81, 1976.

22- KORACEVIC D., KORACEVIC G. and DJORDJEVIC V.: "Method for the measurement of antioxidant activity in human fluids". J. Clin. Pathol., 54 (5): 356-61, 2001.

23- SATOH K.: "Serum lipid peroxide in cerebrovascular disorders determine". Clin. A. Chim. Acta, 90 (1): 37-43, 1978.

24- TAYLOR P.C.: "Anti-TNF therapy for rheumatoid arthritis and other inflammatory diseases". Mol. Biotechnol., 19 (2): 153-68, 2001.

25- KING A. and BOWE J.: "Animal models for diabetes: Understanding the pathogenesis and finding new treatments". Biochemical pharmacology, 99: 1-10, 2016.

26- ABDIN A.A., BAALASH A.A. and HAMOODA H.E.: "Effects of rosiglitazone and aspirin on experimental model of induced type 2 diabetes in rats: Focus on insulin resistance and inflammatory markers". Journal of diabetes and its complications, 24 (3): 168-78, 2010. 
27- GODOY-MATOS A.F.: "The role of glucagon on type 2 diabetes at a glance. Diabetology \& metabolic syndrome". 6 (1): 91, 2014.

28- ARTUNC F., SCHLEICHER E., WEIGERT C., FRITSCHE A., STEFAN N. and HAERING H.U.: "The impact of insulin resistance on the kidney and vasculature". Nature Reviews Nephrology, 12 (12): 721, 2016.

29- MOHAMED M.E., HAMMADI S.H. and ABD-EL HAMID M.H.: "The Possible Role of the Incretin Enhancer Sitaglipten, in Renal Ischemic Reperfusion Injury in Type 2 Diabetes Mellitus". Open Journal of Endocrine and Metabolic Diseases, 4 (07): 181, 2014.

30- TAWFIK M.K.: "Renoprotective activity of telmisartan versus pioglitazone on ischemia/reperfusion induced renal damage in diabetic rats". Eur. Rev. Med. Pharmacol. Sci., 16 (5): 600-9, 2012.

31- KUHAD A. and CHOPRA K.: "Attenuation of diabetic nephropathy by tocotrienol: Involvement of NFkB signaling pathway". Life sciences, 84 (9-10): 296-301, 2009.

32- ZHANG X., YANG S., CHEN J. and SU Z.: "Unraveling the regulation of hepatic gluconeogenesis". Frontiers in endocrinology, 9: 802, 2018.

33- CHUKWUNONSO OBI B., CHINWUBA OKOYE T., OKPASHI V.E., NONYE IGWE C. and OLISAH ALUMANAH E.: "Comparative study of the antioxidant effects of metformin, glibenclamide, and repaglinide in alloxan-induced diabetic rats". Journal of diabetes researc, $1-5,2016$

34- BAILEY C.J.: "Metformin effects on micro and macrovascular complications in type 2 diabetes". Cardiovascular drugs and therapy, 22 (3): 215-24, 2008.

35- De BROE M.E., KAJBAF F. and LALAU J.D.: "Renoprotective effects of metformin. Nephron.", 138 (4): 26174, 2018.

36- CORREIA S., CARVALHO C., SANTOS M.S., SEICA R., OLIVEIRA C.R. and MOREIRA P.I.: "Mechanisms of action of metformin in type 2 diabetes and associated complications: An overview". Mini reviews in medicinal chemistry, 8 (13): 1343-54, 2008.

37- SPOSITO A.C., BERWANGER O., De CARVALHO L.S.F. and SARAIVA J.F.K.: "GLP-1RAs in type 2 diabetes: Mechanisms that underlie cardiovascular effects and overview of cardiovascular outcome data". Cardiovascular diabetology, 17 (1): 157, 2018.

38- YOON SIN OH 1 ID and HEE-SOOK JUN: "Effects of Glucagon-Like Peptide-1 on Oxidative Stress and Nrf2 Signaling". Int. J. Mol. Sci., 19, 26; doi: 10.3390, 2018.

39- GREEN B.D., HAND K.V., DOUGAN J.E., et al.: "GLP1 and related peptides cause concentration-dependent relaxation of rat aorta through a pathway involving KATP and cAMP". Archives of biochemistry and biophysics, 478: 136-42, 2008.

40- OKERSON T., YAN P., STONEHOUSE A. and BRODOWS R.: "Effects of exenatide on systolic blood pressure in subjects with type 2 diabetes". American journal of hypertension, 23 (3): 334-9, 2019.

41- EL-GOHARY O.A. and SAID M.A.: "Protective effect of exenatide (glucagon-like peptide-1 receptor agonist) on renal ischemia-reperfusion injury in diabetic rats". Benha Medical Journal, 33: 24, 2016.

42- KRISTINA S. BOYE, FADY T. BOTROS, AXEL HAUPT, BRAD WOODWARD and MAUREEN J. LAGE: "Glucagon-Like Peptide-1 Receptor Agonist Use and Renal Impairment: A Retrospective Analysis of an Electronic Health Records Database in the U.S. Population". Diabetes Ther., 9: 637-50, 2018.

43- REID T.: "Choosing GLP-1 receptor agonists or DPP-4 inhibitors: Weighing the clinical trial evidence". Clinical diabetes, 30 (1): 3-12, 2012.

44- LEVIN and PHILIP A.: "Practical combination therapy based on pathophysiology of type 2 diabetes". Diabetes, metabolic syndrome and obesity: Targets and therapy, 9: $355,2016$. 


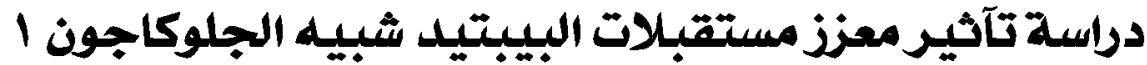

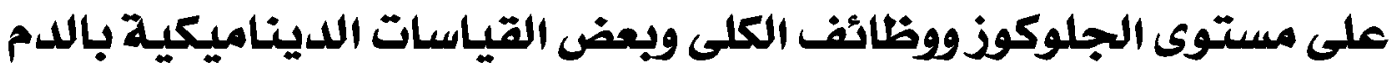

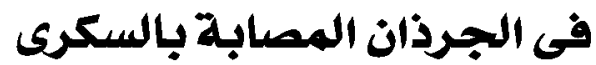

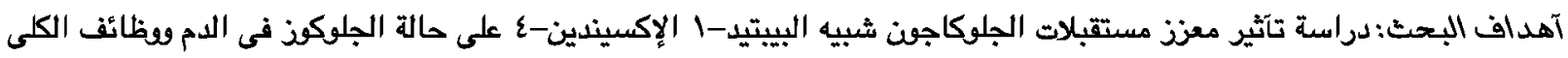

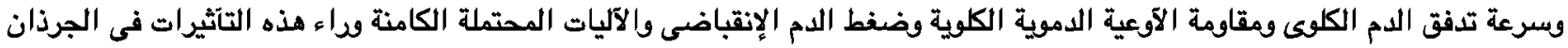

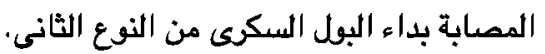

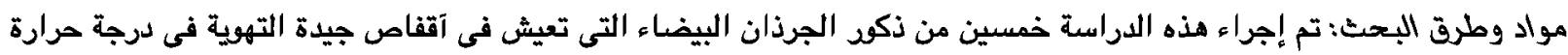

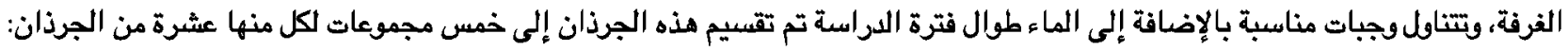

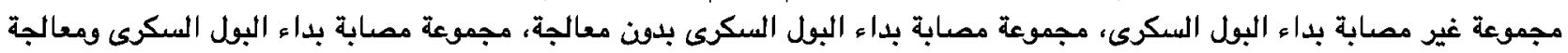

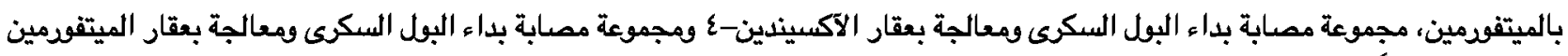
والآكسيندين معاً.

من نتائج الدراسة الحالية، يمكن إستتاج آن:

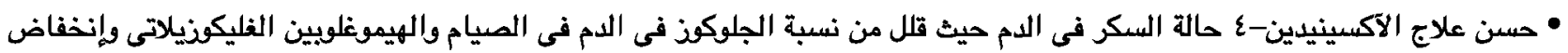

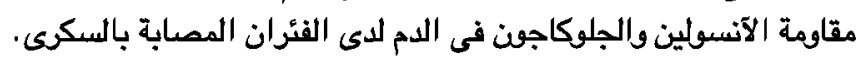

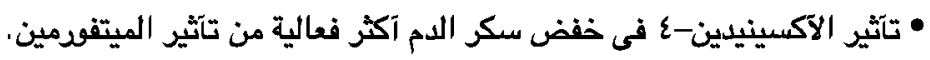

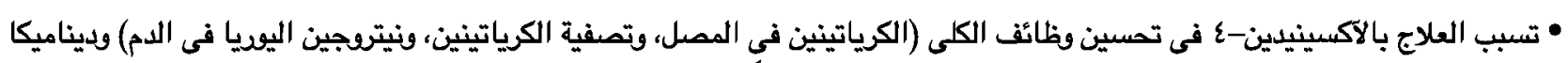

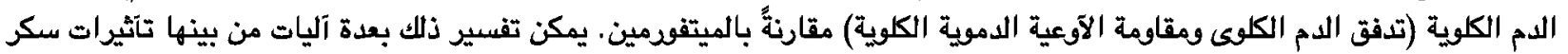
الدم ومضادات الآكسدة والمضادة للإلتهابات.

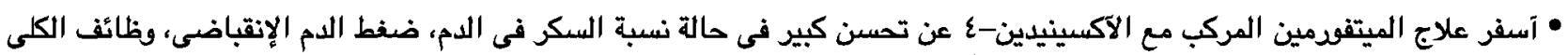

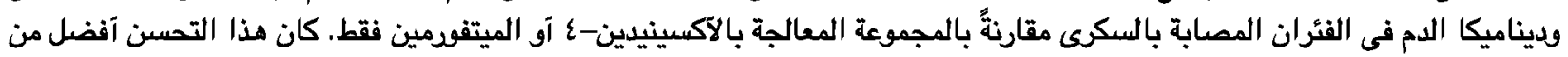

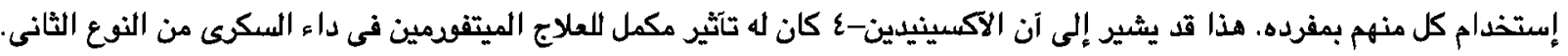

